\title{
Effect of Tidal Cycles on Bacterial Biofilm Formation and Biocorrosion of Stainless Steel AISI 316L
}

\author{
Leslie K. Daille 1,2®, Javiera Aguirre 2,3, Diego Fischer 2,4, Carlos Galarce 2,4,

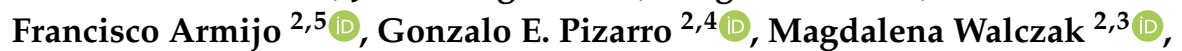 \\ Rodrigo De la Iglesia ${ }^{1,2}$ and Ignacio T. Vargas $2,4, *$ (I)
}

1 Departamento de Genética Molecular y Microbiología, Facultad de Ciencias Biológicas, Pontificia Universidad Católica de Chile, 8330025 Santiago Centro, Santiago, Chile; 1kdaille@uc.cl (L.K.D.); rdelaiglesia@bio.puc.cl (R.D.1.I.)

2 Marine Energy Research \& Innovation Center (MERIC), 7550268 Las Condes, Santiago, Chile; jdaguirr@uc.cl (J.A.); dafische.uc@gmail.com (D.F.); cegalarc@uc.cl (C.G.); jarmijom@uc.cl (F.A.); gpizarro@ing.puc.cl (G.E.P.); mwalczak@ing.puc.cl (M.W.)

3 Departamento de Ingeniería Mecánica y Metalúrgica, Facultad de Ingeniería, Pontificia Universidad Católica de Chile, 7820436 Macul, Santiago, Chile

4 Departamento de Ingeniería Hidráulica y Ambiental, Facultad de Ingeniería, Pontificia Universidad Católica de Chile, 7820436 Macul, Santiago, Chile

5 Facultad de Química y de Farmacia, Pontificia Universidad Católica de Chile, 7820436 Macul, Santiago, Chile

* Correspondence: itvargas@ing.puc.cl; Tel.: +56-226-864-218; Fax: +56-223-545-876

Received: 8 January 2020; Accepted: 12 February 2020; Published: 15 February 2020

check for updates

\begin{abstract}
The effects of tidal cycles associated with the water level on the biocorrosion of stainless steel AISI 316L were studied. Steel coupons were exposed to different conditions of immersion in mesocosms fed by fresh seawater either continuously or in accordance with the periodicity of natural tides. After 5 and 15 weeks, all coupons were found to have undergone ennoblement associated with the formation of a biofilm. Analysis of the composition of the bacterial community using denaturing gradient gel electrophoresis (DGGE) revealed differences in the biological succession. After 15 weeks, exposure to the simulated tidal conditions resulted in biofilms with lesser bacterial richness; the corresponding rate of corrosion, as determined by weight loss, was about 40 times lower compared to the case for the continuous exposure to seawater. Phylogenetic analysis of selected DGGE bands and the inspection of biofilm morphologies revealed that the faster rate of corrosion was associated with the presence of iron-oxidizing Zetaproteobacteria and eukaryotic photosynthetic microorganisms. On the other hand, intermittent exposure to seawater resulted in the succession of microorganisms resistant to the stress associated with sudden environmental changes, which was associated with a low rate of corrosion.
\end{abstract}

Keywords: stainless steel; SEM; polarization; weight loss; microbiological corrosion

\section{Introduction}

Corrosion is a phenomenon involving the degradation of metals in aqueous or moist environments; it results from electrochemical reactions (oxidation/reduction) and is observed during almost all applications of technically relevant alloys. In marine environments, corrosion is enhanced due to the intrinsic characteristics of seawater; most notably, salinity, the presence of nutrients, and the intermittency associated with the tidal variation of the water level are critical factors for the gradual damage of metallic structures, which is occasionally observed in relatively short periods of time [1-5]. Additionally, the presence of highly diverse bacterial communities in marine environments can promote corrosion processes [6] and has been shown to substantially increase the economic expenses, owing 
to direct costs for repairing or preventing the resulting damage [7-9]. In this context, corrosion in seawater is determined by both biotic and abiotic parameters [10]; however, the separation between these two factors is not always clear. For instance, tidal cycles in coastal zones imply variations in specific abiotic characteristics through the change of the effective dissolved oxygen (DO) content, temperature [11], intensity of the shear force imposed by the water flow [1], intensity of UV exposure, and concentration of aggressive chemical species due to evaporation [12]. All these abiotic variations can also affect the development of microbial biofilms and modify the redox reactions that take place at the biofilm/metal interface [13-17].

Biofilm formation could potentially result in microbially influenced corrosion (MIC), also referred to as biocorrosion, changing the chemical conditions of the metal surface. This alteration results in the acceleration of the corrosion process, conditioning the mechanical resistance of the affected structure $[18,19]$. The effects of biofilms can be direct, i.e., through the metabolic activities of the microorganisms, or indirect, i.e., through the patchwork structure that produces electrochemical heterogeneity $[10,20]$. In any case, microbial biofilms on stainless steel have been reportedly associated with shifting the open circuit potential (OCP) towards positive values, which is often referred to as surface ennoblement [21-23]. This ennoblement observed after immersion in natural seawater [23], however, does not imply that the alloy is more resistant to corrosion. Because corrosion resistance of stainless steel relies on the protective layer of Cr-oxides, OCPs closer to the pitting potential increase the probability of localized corrosion that is initiated by pitting [24]. The transition from ennoblement to accelerated corrosion is associated with an increased rate of oxygen reduction at the cathodic zones formed due to the heterogeneity of the biofilm [25].

Within a developed biofilm, microenvironments generated by microbial activity promote microbial growth, increase microbial protection against biocides and predation, and generally favor microbial interaction [26]. In this sense, modifications of abiotic conditions through tidal cycles impose an external pressure on the development of microbial biofilms and their corrosive effect [27]. Although corrosion in marine environments has been extensively studied over the past few decades $[21-23,28]$ and numerous strategies for mitigating corrosion have been proposed $[29,30]$, the roles of the diversity and complexity of the microbial communities in MIC have not yet been fully understood [31]. At the same time, the development of biological characterization tools in the past few years has provided important insights into specific marine bacterial groups and their significance in biocorrosion under controlled laboratory conditions [32-35]. More recent studies based on complete community approaches have finally revealed the complexity of real microbial systems and paved the way for a more systematic understanding of the biocorrosion phenomenon [36-40]. The current understanding is that biocorrosion associated with biofilm formation and growth in natural environments is a complex process; the nonlinearity of this process is determined by numerous factors, of both the abiotic and biotic types. The interaction among these factors, along with the complexity of the biofilms, may alter the electrochemical conditions, thereby weakening, or even inhibiting the biocorrosion process [41]. However, once an alloy-environment system is selected, the effect of the variation in environmental conditions is the most significant. In this context, there is little information on how local fluctuations associated with tidal cycles (e.g., temperature, desiccation cycles, DO) may affect microbial colonization, biofilm formation, and, subsequently, MIC.

In this study, we aim at understanding the effects of tidal cycle modulation on the biocorrosion of stainless steel often used in coastal marine environments, i.e., AISI 316L. Our working hypothesis is that the environmental variability imposed by tidal cycles results in the selection of specific types of bacteria within the biofilms formed on the stainless-steel surface, thereby influencing the development of corrosion. Under this framework, it is expected that the bacterial community formed following the exposure of stainless steel to tidal cycles will have a distinct composition compared to that formed following the continuous immersion of stainless steel in seawater, owing to the significant change of the abiotic conditions. 


\section{Materials and Methods}

\subsection{Material}

The test coupons were prepared from a commercial sheet of stainless steel AISI 316L having a thickness of $3 \mathrm{~mm}$. The chemical composition of the material was determined by glow discharge emission spectrometry bulk analysis (GDA 750 HR, Spectruma, Hof, Germany) to be (in wt $\%$ ): $0.01 \%$, $17.5 \% \mathrm{Cr}, 10.4 \% \mathrm{Ni}, 2.3 \% \mathrm{Mo}, 1.98 \% \mathrm{Mn}, 0.4 \% \mathrm{Si}$, and $67.41 \% \mathrm{Fe}$. Coupons that were $10 \times 2 \mathrm{~cm}$ in size were cut from the original sheet by lathe machining under cooling conditions. Prior to the exposure to seawater, the surface of each coupon was ground using emery paper (grit 240), treated ultrasonically to eliminate any adhering particles, rinsed with distilled water, degreased with acetone, and dried by blowing hot air, according to ASTM G1-03 [42]. The weight of each coupon was measured in triplicate, with a precision of $0.1 \mathrm{mg}$, using an analytical balance (BP221S, Sartorius, Göttingen, Germany).

\subsection{Experimental Set-Up and Procedure}

The mesocosm exposure set-up was constructed such that it allowed a continuous supply of fresh coastal seawater drawn from a depth of $5 \mathrm{~m}$, which was filtered through a filter with a pore size of $800 \mu \mathrm{m}$. One tank $(53 \times 29 \times 16.5 \mathrm{~cm})$ allowed for a continuous flow of seawater; this has been further referred to as the continuous flow system (CFS). Another tank $(258 \times 62 \times 53 \mathrm{~cm})$ allowed for the simulation of tidal immersion pulses through cycles of filling and draining, mimicking the natural tidal frequency; this tank has hence been referred to as the simulated tide system (STS). During the cycles, flow through the cell was maintained and only the water level was modulated. The set-up was located at the Estación Costera de Investigaciones Marinas (ECIM) of the Pontificia Universidad Católica de Chile, in Las Cruces, Central Chile (Pacific Ocean; 33 30'16" S; 71 $38^{\prime} 23^{\prime \prime}$ W). Both tanks were situated outdoors, protected from direct sunlight by a steel roof. More details regarding the set-up can be found in our preliminary study [43].

In each tank, 18 coupons were mounted on supports distributed equidistantly; each support hosted 6 coupons oriented perpendicular to the direction of the nominal flow through. One support of each rack was sampled after 1 day, 5 weeks, and 15 weeks of exposure, corresponding to 2, 70, and 210 tidal cycles, respectively, for the STS. The reference sample corresponded to a prepared, but unexposed coupon. At each sampling time, water quality parameters ( $\mathrm{pH}$, dissolved oxygen, conductivity, and temperature) were determined using a multi-parameter digital meter (HQ40dTM; HACH Company, Loveland, CO, USA), revealing that the overall variations of temperature, $\mathrm{pH}$, conductivity, and DO concentration were $13.75 \pm 2.19^{\circ} \mathrm{C}, 7.93 \pm 0.13,54.26 \pm 2.06 \mathrm{mS} \cdot \mathrm{cm}^{-1}$, and $9.30 \pm 1.27 \mathrm{mg} \mathrm{L}^{-1}$, respectively.

\subsection{Corrosion Testing}

For evaluating the corrosion performance, both weight loss and OCP measurements were performed per system in each sampling time. For the weight loss measurement, 3 fresh coupons were sonicated for $5 \mathrm{~min}$ in $50 \mathrm{~mL}$ of sterile seawater (Elmasonic S 30H, Elma Schmidbauer GmbH, Cologne, Germany) per each sampling time as harvested, to release the biological material present on the metal surface. The supernatants were collected for biological analysis (see Section 2.5), while the coupons were washed and scrubbed with a non-metallic bristle brush to remove any corrosion products from the surface. Finally, the samples were degreased with acetone, dried with hot air, and weighed in accordance with ASTM G1-03 [42]. The average corrosion rate, in $\mathrm{mg} \cdot \mathrm{cm}^{-2}$ and $\mathrm{mm} \cdot \mathrm{year}(\mathrm{yr})^{-1}$, was calculated from the weight loss data. In particular, the corrosion rate in $\mathrm{mm} \cdot \mathrm{yr}^{-1}$ units was calculated as following [42]:

$$
\text { Corrosion Rate }=\frac{(\mathrm{K} \times W)}{(\mathrm{A} \times \mathrm{T} \times \mathrm{D})}
$$

where $\mathrm{K}$ is a constant $\left(8.76 \times 10^{4}\right)$, $\mathrm{T}$ is the time of exposure in hours, $\mathrm{A}$ is the area in $\mathrm{cm}^{2}, \mathrm{~W}$ is the mass loss in grams, and D is the material density in $\mathrm{g} / \mathrm{cm}^{3}$. 
For OCP measurements, one fresh coupon per each sampling time was used as harvested. The coupons were transferred into a three-electrode set-up comprising an electrochemical cell filled with $50 \mathrm{~mL}$ of seawater filtered using a $0.2-\mu \mathrm{m}$ filter. The cell configuration enabled the exposure of $1.3 \mathrm{~cm}^{2}$ of the coupon surface through the use of a Teflon mask that allows the electrochemical cell to be placed on the $2 \mathrm{~cm}$ wide coupon. The selected area, around the middle of the coupon, was representative in terms of the biofilm developed on the surface. The coupon was connected as the working electrode, a graphite rod was used as a counter electrode and $\mathrm{Ag} / \mathrm{AgCl}$ (saturated $\mathrm{KCl}$ ) electrode, as a reference. The set-up was secured with the clamp system provided by the electrochemical cell (PTC1 ${ }^{\mathrm{TM}}$ Paint Test Cell, Gamry Instruments, Warminster, PA, USA). The reference sample (unexposed to the experimental system) was analyzed in this set-up immediately after the preparation of the metal surface (described in Section 2.1).

\subsection{Morphological Surface Characterization}

For biofilm characterization analyses, the coupons were fixed using $2 \%$ glutaraldehyde solution prepared using previously filtered natural seawater $(0.2-\mu \mathrm{m}$ filter, to remove microorganisms), and stored at $4{ }^{\circ} \mathrm{C}$ until observation. The critical point drying method was used to avoid damage of the cells within the biofilm, using a NEWMED FJVA Critical Drying System Model CPDS-2002. Solvent replacement with liquid $\mathrm{CO}_{2}$ was performed according to Schädler et al. [44]. The critical point dried samples were coated in a Varian Vacuum Evaporator PS10E (Varian Inc., Palo Alto, CA, USA) with 40-carat gold. The coating thickness was approximately $20 \mathrm{~nm}$. Samples were analyzed using a scanning electron microscope (SEM) (LEO 1420VP, LEO Electron Microscopy Inc., Thornwood, NY, USA). The samples surfaces were thoroughly inspected utilizing $500 \times, 2500 \times$, and $10,000 \times$ magnifications. Representative images of three different fields were selected to show the morphology of the cells at $10,000 \times$ magnification.

\subsection{DNA Extraction and Denaturing Gradient Gel Electrophoresis (DGGE)}

The supernatant solutions of the three replicates (described in Section 2.3) were filtered through a 0.2- $\mu \mathrm{m}$ filter (polyethersulfone, Merck-Millipore, Burlington, MA, USA) for subsequent DNA extraction. The extraction was carried out with a Phenol: Chloroform protocol [45], and the integrity of the DNA was checked by $0.8 \%$ agarose gel electrophoresis. Then, DNA quantification was performed using the Qubit ${ }^{\circledR}$ 2.0 Fluorometer (Invitrogen ${ }^{\mathrm{TM}}$, Life Technologies, Carlsbad, CA, USA), according to the manufacturer's protocol.

At each sampling time, $2 \mathrm{~L}$ of the seawater feeding the mesocosms was collected and filtered through $0.2-\mu \mathrm{m}$ filters; the filters were analyzed to evaluate the total free-living bacterial pool.

Bacterial community composition was determined by Denaturing Gradient Gel Electrophoresis (DGGE) of the PCR-generated 16S rRNA gene amplicons, which were obtained using the GC358F and 907R primers [46] using a pooled sample of the three replicates as the template. The resulting fragments were resolved on a $6 \%(w / v)$ polyacrylamide gel containing a denaturing gradient of $70 \%-40 \%$ urea-formamide. The DGGE was performed in $1 \times$ TAE buffer ( $40 \mathrm{mM}$ Tris, $20 \mathrm{mM}$ acetic acid, and $1 \mathrm{mM}$ EDTA) for $10 \mathrm{~min}$ at $60^{\circ} \mathrm{C}$ and $100 \mathrm{~V}$, and then for $17 \mathrm{~h}$ at $75 \mathrm{~V}$ in a DCode ${ }^{\mathrm{TM}}$ Universal Mutation Detection System (BioRad Laboratories, Inc., Hercules, CA, USA). After the electrophoresis, the gel was dyed with a solution of SYBR ${ }^{\circledR}$ Gold Nucleic Acid Gel Stain (Molecular Probes ${ }^{\circledR}$, Life Technologies, Carlsbad, CA, USA). The DGGE gel was then observed on a UV transilluminator (at a wavelength of $312 \mathrm{~nm}$ ) and photographed with a digital camera (Canon PowerShot A650 IS, Canon Inc., Tokyo, Japan). Invert greyscale images were prepared using the Adobe Photoshop CS6 software (Adobe Systems, San Jose, CA, USA). To determine the similarity between the bacterial community compositions in the different samples, the main DGGE bands were selected, excised, and eluted overnight in $20 \mu \mathrm{L}$ of sterile Milli-Q water, and then re-amplified using the same primers. The re-amplified bands were purified and sequenced by Macrogen, Inc. (Seoul, Korea). 


\subsection{Bioinformatics and Statistical Analyses}

The bands obtained through the DGGE analysis were used for building a presence/absence matrix. This biological data matrix was subjected to hierarchical cluster analysis and Non-metric Multidimensional Scaling (NMDS), based on Bray-Curtis similarities implemented in the Primer v6.1.7 software (Primer-E, Plymouth, UK). The DGGE band sequences were edited using Mega6 software [47] and chimeras, if any, were discarded using the Bellerophon program [48]. The sequences were compared against those published in the NCBI GenBank database (release April 2016) using the Blastn algorithm [49]. The evolutionary history was inferred by using the Maximum Likelihood method based on the Tamura-Nei model [50]. The initial trees for the heuristic search were obtained by applying the Neighbor-Joining method to a matrix of pairwise distances estimated using the Maximum Composite Likelihood approach. The obtained trees were drawn to scale, with branch lengths measured as the number of substitutions per site. The analysis involved 57 nucleotide sequences. All positions containing gaps and missing data were eliminated. There was a total of 400 positions in the final dataset. Evolutionary analyses were performed using the MEGA6 software, version 6.0 [47]. Finally, the analyzed sequences were deposited in GenBank under the accession numbers from MG736929 to MG736956.

\section{Results}

\subsection{Microbial Cell Morphologies within the Biofilms}

The morphology of the preserved microbial cells within the biofilms was observed using SEM. Figure 1 summarizes the representative microbial cell morphologies observed on the biofilms developed after 1 day, 5 weeks and 15 weeks of exposure to seawater in the CFS and STS mesocosms. Though time an increase of the biomass was observed in both systems (Figure 1A-C). The analysis revealed that the CFS biofilm was colonized by bigger microbial organisms; among them, diatoms were identified based on its morphologic characteristics (Figure 1C). On the other hand, the STS biofilm showed more bacterial like morphologies, specifically bacterial rods entangled in a matrix-like structure (Figure 1D-F). 
CFS
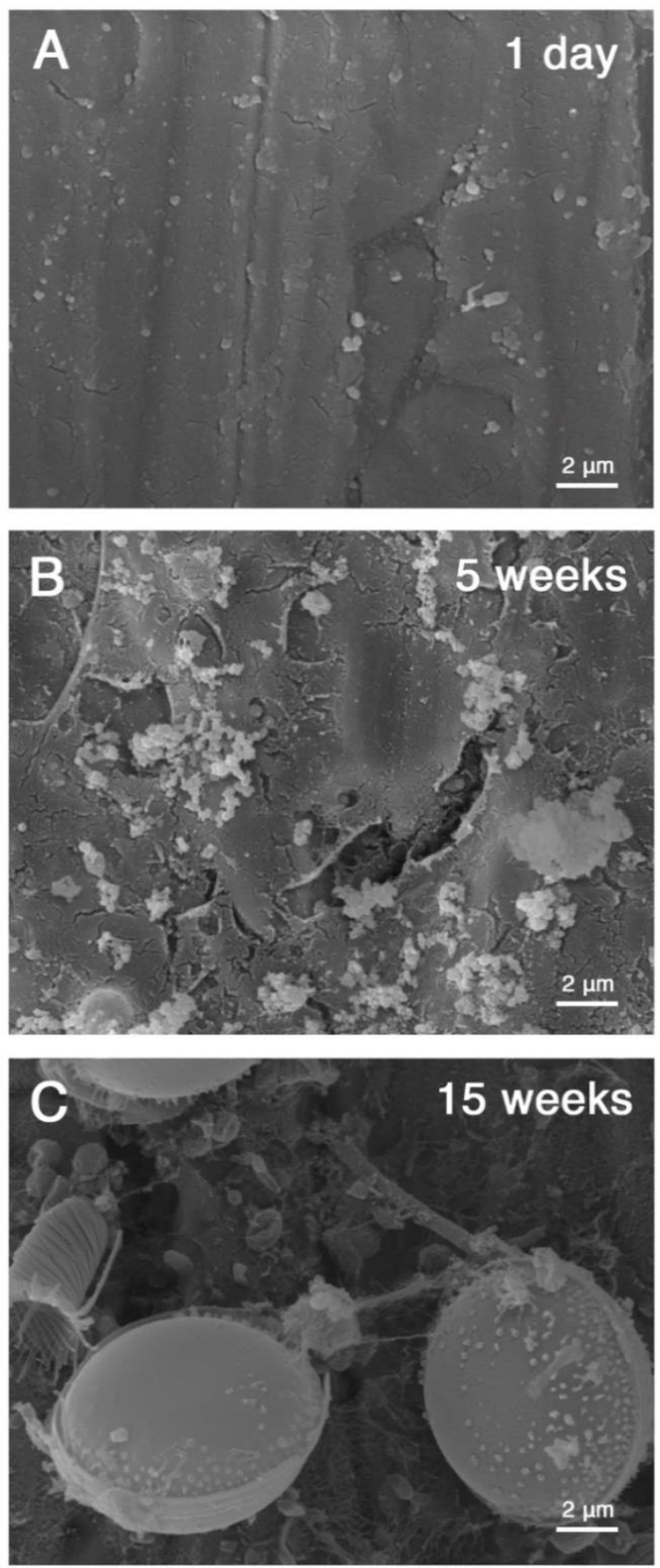

STS
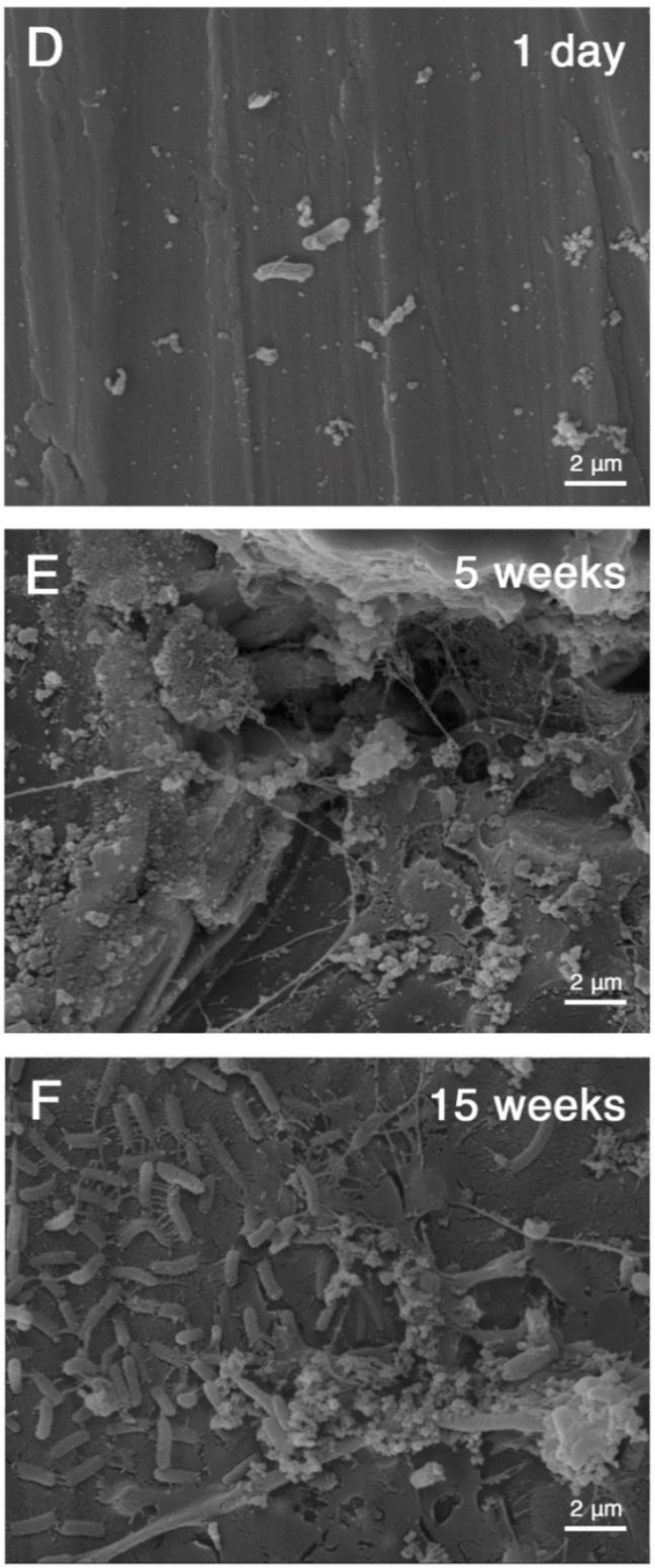

Figure 1. Scanning electron micrographs of the biofilms formed over stainless steel AISI 316L after exposure to natural seawater. (A-C) Continuous flow system (CFS) exposure, (D-F) stimulated tide system (STS) exposure. Images had scale bars of $2 \mu \mathrm{m}$ that correspond to magnifications of $10,000 \times$.

\subsection{Bacterial Community Composition}

The results of the 16S rRNA gene sequencing analysis obtained from DGGE are shown in Figure 2, along with the corresponding similarity analysis. In general, the diversity of the bacterial community composition changed over time, but these changes followed different patterns after the continuous and intermittent exposures to seawater; the bacterial diversity in both these cases was different from that observed in the source seawater at the corresponding time points. In particular, after two tidal 
cycles (1 day), a number of similar core bands were observed in case of samples exposed to seawater in both the mesocosms, with only a few bands being detected in case of the STS biofilm (bands 15, 16 , and below). Some of the core bands were also present in the source seawater at the same time but at different relative intensities. At the longer times of exposure, the number of DGGE gel bands increased in the case of the CFS biofilm, while the reverse trend was observed for the STS biofilm, in which case most of the intensity was concentrated in band 20 at the end of the exposure time. The DGGE band pattern of the surrounding seawater showed little change during the time between the first two sampling times, while the shift of relative intensities was more pronounced at the end of the experiment.

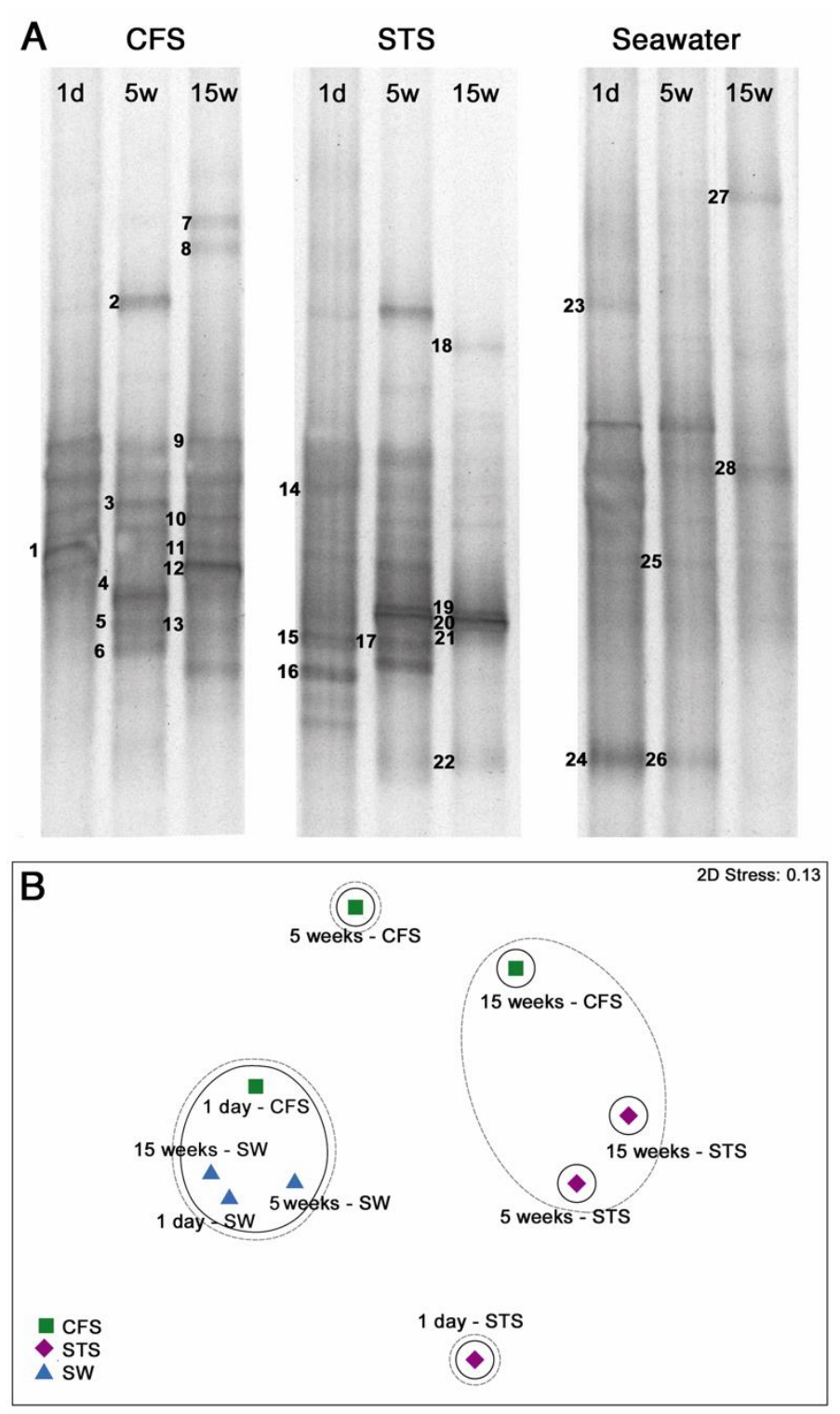

Figure 2. Analysis of the bacterial communities in the biofilms. (A) Denaturing gradient gel electrophoresis (DGGE) profiles of 16S rRNA gene sequences from biofilms formed during CFS and STS exposure, compared with the bacterial communities present in bulk seawater at the same time. The numbers indicate the sequenced bands (Table S1, Supplementary information); (B) Non-metric Multidimensional Scaling (NMDS) plot representing the analysis of the similarity of S17 Bray-Curtis resemblances between samples from the CFS biofilm, STS biofilm, and seawater (SW). Similarities based on the cluster analysis and SIMPROF test are encircled by a continuous line $(60 \%)$ and dashed line $(40 \%)$, respectively. 
NMDS analysis based on the presence/absence of DGGE bands indicated that the similarity between the bacterial communities in the biofilms and those present in seawater decreased with the increase in exposure times (Figure 2B). The difference was the most evident during the first day of exposure; the bacterial community compositions of the CFS and STS biofilms showed only $40 \%$ and $20 \%$ similarity with that of the feed water, respectively. Similarities within the bacterial community compositions of the STS and CFS biofilms developed from the 5th to the 15 th week were $40 \%$ and $20 \%$, respectively. The bacterial community in bulk seawater maintained a similarity of $60 \%$ over time.

\subsection{Bacterial Community_Phylogenetic Analysis of the Main Members}

The representative DGGE bands were re-amplified, sequenced, and compared against the GenBank database; the taxonomic identity of each sequence is summarized in Table S1 (Supplementary material). The results of the phylogenetic analysis are shown in Figure 3. The sequencing analysis of the bands from the CFS biofilm revealed that the bacterial community was generally dominated by members from the phylum Proteobacteria, whereas the bands of the STS biofilm yielded sequences associated with members from Flavobacteriia/Bacteroidetes.

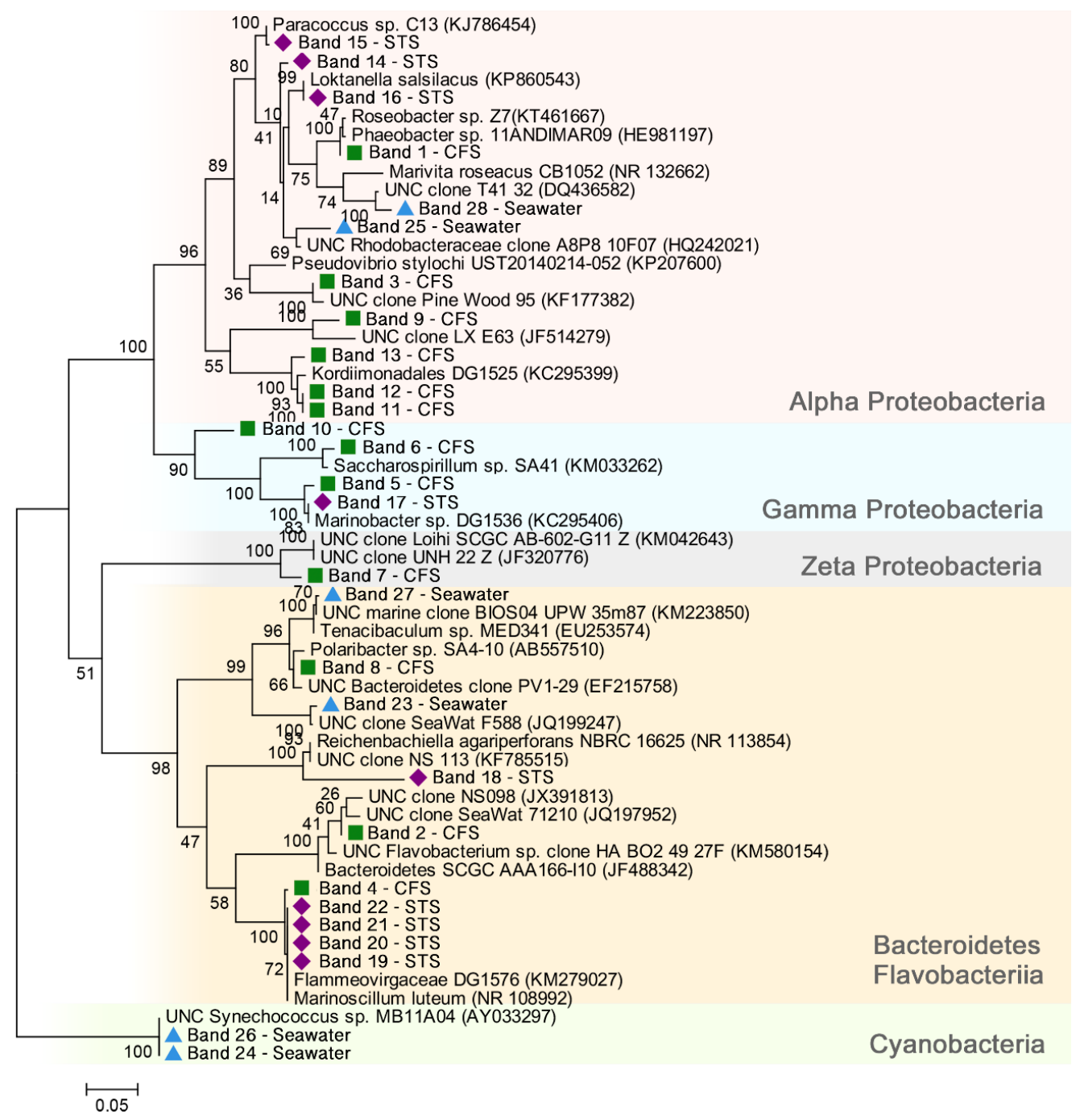

Figure 3. Phylogenetic analysis of the selected DGGE strains. Molecular phylogenetic analysis based on partial sequences of the $16 \mathrm{~S}$ rRNA gene selected by the maximum likelihood estimation method. The tree with the highest log likelihood $(-4806.8854)$ is shown. The numbers at the left-hand side of each tree branch indicate the percentage of taxa clustered together in the branch. 
After one day of exposure, the CFS and STS biofilms hosted bacteria from the class Alphaproteobacteria, as indicated by the bands CFS-1, STS-14, STS-15, and STS-16; however, these bacteria belonged to different genera. After five weeks of exposure to seawater, sequences belonging to bacteria from the class Gammaproteobacteria were seen in the case of both the biofilms. Finally, after 15 weeks of exposure to seawater, the bacterial community of the STS biofilm was displaced to a very distinctive profile, strongly dominated by members from the class Flavobacteriia in the phylum Bacteroidetes (band STS-18-STS-22) that were affiliated to the genus Reichenbachiella in the family Flammeovirgaceae; these were not present in the CFS biofilms. The CFS biofilm remained dominated by bacteria associated with the phylum Proteobacteria. The appearance of bacteria from the class Zetaproteobacteria at the last exposure time (band CFS-7) following continuous exposure to seawater was not observed in the case of the STS biofilm at any of the sampling times.

\subsection{Corrosion Performance}

The weight loss data (Figure 4) revealed a loss of material seven times greater in the CFS-exposed coupons compared to STS at five weeks. This difference was consistent for the entire exposure period, with average losses of $4.9 \pm 1.4 \mathrm{mg} \mathrm{cm}^{-2}$, compared to the weight loss in the STS-exposed coupons $\left(0.1 \pm 0.2 \mathrm{mg} \mathrm{cm}^{-2}\right)$, i.e., forty times greater, after 15 weeks of exposure. The corrosion rate derived from the weight loss (Table 1) was about twenty-six times higher for samples exposed to seawater in the CFS mesocosms compared to samples in the STS mesocosms after the end of the exposure.

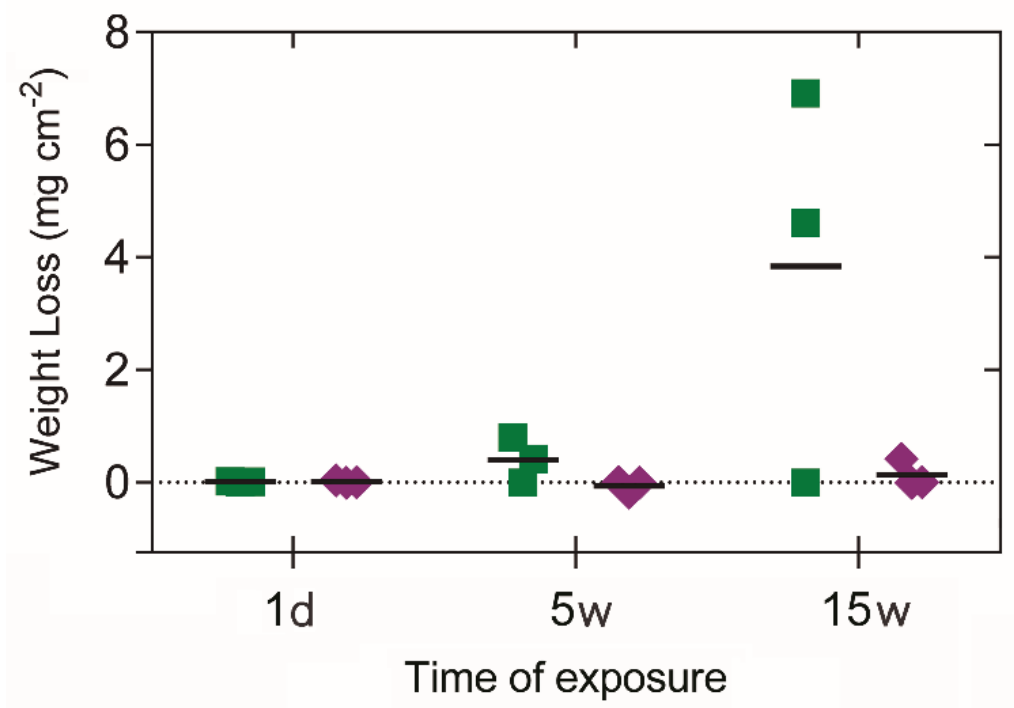

Figure 4. Weight loss of coupons exposed to seawater in the CFS ( $\square$, green) and STS $(\diamond$, purple) set-up. The sampling times were 0.1 (1 day), 5, and 15 weeks. w: weeks.

Table 1. Electrochemical and deterioration analysis of stainless steel 316L after exposure to natural seawater.

\begin{tabular}{|c|c|c|c|}
\hline Samples & Time & OCP (V vs. Ag/AgCl) & Corrosion Rate $^{a} \pm \mathrm{SD}\left(\mathrm{mm} \cdot \mathrm{yr}^{-1}\right)$ \\
\hline \multirow[t]{2}{*}{ Reference } & - & -0.02 & - \\
\hline & $1 d$ & ND & $0.0046 \pm 0.0045$ \\
\hline \multirow[t]{3}{*}{ CFS } & $5 w$ & +0.25 & $0.0047 \pm 0.0046$ \\
\hline & $15 w$ & +0.28 & $0.0148 \pm 0.0135$ \\
\hline & $1 d$ & ND & $0.0063 \pm 0.0066$ \\
\hline \multirow[t]{2}{*}{ STS } & $5 w$ & +0.01 & $0.0007 \pm 0.0012$ \\
\hline & $15 \mathrm{w}$ & +0.17 & $0.0006 \pm 0.0009$ \\
\hline
\end{tabular}

${ }^{\mathrm{a}}$ Corrosion rate determined from weight loss (precision $\left.=0.0001 \mathrm{~g}\right)$. ND: Not determinate. 
After exposure to seawater in the CFS mesocosm, the OCP on the coupons presented an increment of $0.2 \mathrm{~V}$ as compared to the value prior exposure. This value remained steady after 5 and 15 weeks. Whereas, OCP values for coupons exposed in STS mesocosm presented a smaller displacement than those observed in the case of CFS, but increasing in time, with values of 0.01 and $0.17 \mathrm{~V}$ corresponding to 5 and 15 weeks of exposure, respectively.

\section{Discussion}

The microbial cell morphologies observed within the biofilms formed initially on the stainless steel were similar in the samples exposed to seawater in both the CFS and STS mesocosms. Nevertheless, during the course of the exposure, dissimilar microbial cell morphologies were observed and identified to belong to distinctive bacterial communities according to the molecular analysis. The CFS biofilm presented photosynthetic eukaryotic microorganisms identified through morphology along with the bacterial community highly dominated by members from the Alphaproteobacteria and Gammaproteobacteria classes. Whereas the STS biofilm presented morphologies classically associated with bacterial rods, and it was dominated by members of Bacteroidetes/Flavobacteria. This biological differentiation is consistent with the registered values of OCP, indicative of ennoblement by the shift towards more anodic potentials (Table 1). The presence of specific types of microorganisms could be responsible for the observed electrochemical behavior as demonstrated by Li et al. [51] for the case of B. cereus biofilms on the surface of 316L stainless steel. However, the richness of the natural biofilm makes it difficult to disentangle the contribution of individual species and requires additional analysis.

The bacteria from the Alphaproteobacteria and Gammaproteobacteria classes that were identified in the biofilm settled initially in both the mesocosms have been described in the literature as the primary colonizers on a variety of material, such as acryl, glass, steel, and polyvinyl chloride (PVC) [52-54]. After five weeks of exposure, the main groups of bacteria identified in both the types of mesocosms were aerobic, noting that members from the phylum Bacteroidetes and the class Gammaproteobacteria have been reported to be involved in the corrosion of steel in seawater [55] One of the mechanisms associated with these groups of bacteria has been related to the production of the oxidase enzyme, which is known to reduce the oxygen concentration of the surrounding environment. This suggests that the presence of these kinds of bacteria generated diverse microenvironments on the surface with different oxygen concentrations, thereby modifying the chemical reactions on the metal surface. Accordingly, after 15 weeks of exposure in the CFS mesocosms, the appearance of bacteria from the Zetaproteobacteria class in the biofilms indicates the development of anoxic microenvironments at the metal-biofilm interface. This group of proteobacteria has been reported by Makita et al. [56] to be isolated from seawater and capable of colonizing carbon steel within 10 days [57], causing accelerated corrosion. Although bacteria from the Zetaproteobacteria class were not found on 316L stainless steel after two weeks in a targeted experiment involving the exposure to seawater [58], they can be expected to take longer to emerge through biological succession [57,59]. Such a delay may explain the increased bacterial community richness observed in the CFS biofilm with the increase in the exposure time. On the other hand, after 15 weeks of exposure, the STS biofilm was dominated by members from the phylum Bacteroidetes that belongs to the family Flammeovirgaceae; these bacteria have been described to be capable of resisting shear forces and radiation, which enables their growth in environments with variable conditions for respiration and their locomotion by means of gliding motility [60]. One of these members, bacteria from the genus Reichenbachiella were present in the STS biofilm after 15 weeks of exposure. Considering that in the present study, the same material has been used in different exposure systems feed with the same source of natural seawater, it can be hypothesized that the strong variation of abiotic factors associated with the intermittency of the water level in the STS mesocosm led to the selection of bacterial groups that were more tolerant to sudden environmental changes. Studying these types of microorganisms under conditions of environmental changes remains, however, challenging due to a high number of possible cross-effects and different time scales involved in the processes [61]. 
The electrochemical response of the 316L stainless-steel coupons covered by biofilms was distinctive in the two exposure systems. Although, in both cases, an increase in OCP values were observed, the ennoblement in the case of CFS was greater as compared to STS, with particularly significant discrepancy after five weeks of exposure. The effect of ennoblement has been frequently reported in studies for passive alloys, including stainless steels, in exposure to natural seawater [9,21-23], and explained by the modification in the kinetics of electrochemical reactions. However, in the presence of marine biofilms, both anodic and cathodic reactions may contribute to the onset of ennoblement since both oxygen reduction reaction and the anodic metal dissolution are subject to possible alternation by the sheer presence of active interaction with biofilms constituents. Further, an increase in the OCP values of the material might suggest an increased risk of developing pitting corrosion [23]. However, it is not the case in our study since the visual inspection of the coupons prepared for weight loss analysis showed no evidence of pitting (see Figure S1, Supplementary Material). Therefore, the biofilm developed on the metal surface under both types of immersion conditions is deduced to be a uniform-type of corrosion.

The increase in the corrosion rate after five weeks of exposure in both the mesocosms was consistent with the presence of aerobic bacteria detected in both the systems at this time. After 15 weeks of exposure, the 316L steel had lost about 40 times the mass in the CFS set-up, compared to the steel sample subjected to intermittent exposure to seawater in the STS set-up. In particular, the increased weight loss observed in the case of the CFS exposure is consistent with the presence of members from the class Zetaproteobacteria and the presence of eukaryotic photosynthetic microorganisms observed in the SEM analysis. On the other hand, the absence of microorganisms able to produce oxygen within the STS biofilm could partially explain the lower corrosion rate observed in this case. Because the biofilm could act as an effective diffusion barrier for the main cathodic reactant, i.e., dissolved oxygen, its lower availability at the biofilm/metal interface results in a smaller corrosion current. The biofilm may also have inhibitive properties, as reported in the case of Vibrio neocaledonicus [62]. Additionally, it should be noted that the difference in weight loss after 15 weeks is disproportional with the time of effective exposure to the flowing seawater. Considering that the coupons in the CFS set-up were twice as long underwater compared to those in the STS set-up, only half of the difference in the corrosion rate could be attributed to the immersion time, which is an abiotic factor. Although this abiotic factor may have had a non-linear effect on the abiotic growth of the passive layer, not quantified in this study, its qualitative effect on the biofilm composition was evident. The selection of microorganisms conditioned by the dry/wet cycles is then concluded to be a significant factor contributing to biocorrosion.

Finally, the biocorrosion testing method and its implications are discussed. In order to determine the effect of tidal intermittency on corrosion, the approach of constructing mesocosms fed by natural seawater was adopted in our study. This way, all the abiotic contributions could be reduced to the effective time of immersion. However, in practical applications, the contributions of temperature, oxygenation, and salinity should also be considered. This study shows that when all conditions except for the intermittency of immersion are equal, protection against corrosive biofilms can be established by the biological succession of microorganisms from the same seawater feed. The selection of iron-oxidizing bacteria on steel surfaces seems inevitable in the long run, but the sudden environmental changes associated with tidal intermittency privilege the succession of species more resistant to stress. These species were shown to form biofilms that were more protective for the AISI 316L alloy, but these results should not be readily extrapolated for other steel alloys. Notwithstanding, the bacterial community analysis approach has been shown to be helpful for understanding corrosion in terms of the biofilm effect and may further be developed as a practical method for predicting material performance.

\section{Conclusions}

In this study, stainless steel AISI 316L was exposed to either simulated tidal conditions or a continuous flow of natural seawater of the Southeast Pacific. The results showed that the effect of tidal cycles is determined by biotic factors rather than the direct difference in the time of immersion. 
In particular, higher ennoblement of the stainless steel was associated with a biological succession of bacteria selected from the seawater feed. The significantly lower corrosion rate observed in samples exposed to simulated tidal conditions was associated with the dominance of bacterial-like cells present throughout the metal surface, rather than photosynthetic eukaryotic microorganisms as observed under continuous exposure to natural seawater. Finally, the bacterial communities of the biofilm developed under simulated tidal conditions were more tolerant of sudden environmental changes providing apparent protection for the stainless steel against corrosion. Further research on the specific conditions that triggered these metabolic differences in microbial communities associated with tidal cycles could contribute to developing new tools to prevent the biodeterioration of stainless steel exposed to natural seawater.

Supplementary Materials: The following are available online at http://www.mdpi.com/2077-1312/8/2/124/s1, Table S1: sequence similarities of bacterial bands excised from DGGE, Figure S1: Visual analysis of the coupons after exposure to natural seawater. Representative images of visual inspection of the 316L stainless steel coupons that were under different conditions: (i) Reference, coupons not exposed to natural seawater. (ii) CFS, coupons continuously exposed to natural seawater for 5 and 15 weeks. (iii) STS, coupons exposed to simulated tidal conditions for 5 and 15 weeks.

Author Contributions: Conceptualization, L.K.D., R.D.1.I., I.T.V.; All authors contributed to methodology, formal analysis and investigation; writing — original draft preparation, L.K.D.; writing—review and editing, J.A., D.F., C.G., F.A., G.E.P., M.W., R.D.I.I., I.T.V. All authors have read and agreed to the published version of the manuscript.

Funding: This research was funded by the Vicerrectoría de Investigación de la Pontificia Universidad Católica de Chile (Project VRI-PUC N ${ }^{\circ} 01 / 2013$ ), FONDECYT project 1181326 and Office Naval Research (Grant NICOP-N62909-17-1-2012). The authors also acknowledge the support provided by CONICYT through FONDEQUIP EQM160091. This study was conducted at the Marine Energy Research and Innovation Center (MERIC) (Project CORFO 14CEI2-28228).

Acknowledgments: We offer special thanks to Charline Tessereau, Katherine Rojas, and Francisca Rubio for their assistance in the laboratory and help with sample preparation. In addition, Leslie Daille, Javiera Aguirre, and Carlos Galarce acknowledge CONICYT for their doctoral scholarships CONICYT-PCHA/Doctorado Nacional/2014-21140415, 2015-21150171, and 2013-21130365, respectively.

Conflicts of Interest: All authors declare no conflict of interest or any financial and personal relationships with other people or organizations that could inappropriately influence (bias) this work.

\section{References}

1. Pugh, D.T. Tides, Surges and Mean Sea-Level, 1st ed.; John Wiley \& Sons: Hoboken, NJ, USA, 1987; ISBN 0-471-91505-X.

2. European Federation of Corrosion. A Working Party Report on Marine Corrosion of Stainless Steels: Chlorination and Microbial Effects; Woodhead Pub Ltd.: Cambridge, UK, 1993; ISBN 0901716332.

3. European Federation of Corrosion. Marine Corrosion of Stainless Steels; Feron, D., Ed.; IOM Communications, Maney Publishing: Leeds, UK, 1993; ISBN 1861251513.

4. Melchers, R. Effect on marine immersion corrosion of carbon content of low alloy steels. Corros. Sci. 2003, 45, 2609-2625. [CrossRef]

5. Melchers, R.E. Long-term immersion corrosion of steels in seawaters with elevated nutrient concentration. Corros. Sci. 2014, 81, 110-116. [CrossRef]

6. Païssé, S.; Ghiglione, J.F.; Marty, F.; Abbas, B.; Gueuné, H.; Amaya, J.M.S.; Muyzer, G.; Quillet, L. Sulfate-reducing bacteria inhabiting natural corrosion deposits from marine steel structures. Appl. Microbiol. Biotechnol. 2013, 97, 7493-7504. [CrossRef]

7. Koch, G.H.; Brongers, M.P.H.; Thompson, N.G.; Virmani, P.Y.; Payer, J.H. Corrosion Costs and Preventive Strategies in the United States; NACE International Report FHWA-RD-01; NACE International: Houston, TX, USA, 2002.

8. Stipanicev, M.; Turcu, F.; Esnault, L.; Rosas, O.; Basseguy, R.; Sztyler, M.; Beech, I.B. Corrosion of carbon steel by bacteria from North Sea offshore seawater injection systems: Laboratory investigation. Bioelectrochemistry 2014, 97, 76-88. [CrossRef] 
9. Landoulsi, J.; El Kirat, K.; Richard, C.; Féron, D.; Pulvin, S. Enzymatic Approach of Microbial Influenced Corrosion, a Review Based on Stainless Steel in Natural Seawater. Environ. Sci. Technol. 2008, 42, 2233-2242. [CrossRef]

10. Beech, I.B.; Sunner, J. Biocorrosion: Towards understanding interactions between biofilms and metals. Curr. Opin. Biotechnol. 2004, 15, 181-186. [CrossRef]

11. Dexter, S.C.; Dexter, S.C. Corrosion in Seawater. Environments 2006, 13, 27-41.

12. Lotze, H.K.; Worm, B.; Molis, M.; Wahl, M. Effects of UV radiation and consumers on recruitment and succession of a marine macrobenthic community. Mar. Ecol. Prog. Ser. 2002, 243, 57-66. [CrossRef]

13. Yeo, S.K.; Huggett, M.J.; Eiler, A.; Rappé, M.S. Coastal Bacterioplankton Community Dynamics in Response to a Natural Disturbance. PLoS ONE 2013, 8, e56207. [CrossRef]

14. Eashwar, M.; Subramanian, G.; Palanichamy, S.; Rajagopal, G. The influence of sunlight on the localized corrosion of UNS S31600 in natural seawater. Biofouling 2011, 27, 837-849. [CrossRef]

15. Eashwar, M.; Lakshman Kumar, A.; Sreedhar, G.; Kennedy, J.; Suresh Bapu, R.H. Stainless steel in coastal seawater: Sunlight counteracts biologically enhanced cathodic kinetics. Biofouling 2014, 30, 929-939. [CrossRef]

16. Melchers, R.E.; Jeffrey, R. Corrosion of long vertical steel strips in the marine tidal zone and implications for ALWC. Corros. Sci. 2012, 65, 26-36. [CrossRef]

17. Jeffrey, R.; Melchers, R.E. Effect of vertical length on corrosion of steel in the tidal zone. Corrosion 2009, 65, 695-702. [CrossRef]

18. Hamilton, W.A. Sulphate-Reducing Bacteria and Anaerobic Corrosion. Annu. Rev. Microbiol. 1985, 39, 195-217. [CrossRef]

19. Lichter, J.A.; Thompson, M.T.; Delgadillo, M.; Nishikawa, T.; Rubner, M.F.; Van Vliet, K.J. Substrata mechanical stiffness can regulate adhesion of viable bacteria. Biomacromolecules 2008, 9, 1571-1578. [CrossRef]

20. King, R.A.; Miller, J.D.; Wakerleyt, D.S. Corrosion of Mild Steel in Cultures of Sulphate-Reducing Bacteria. Br. Corros. J. 1972, 8, 89-93. [CrossRef]

21. Beech, I.B.; Sunner, J.A.; Hiraoka, K. Microbe-surface interactions in biofouling and biocorrosion processes. Int. Microbiol. 2005, 8, 157-168.

22. Mansfeld, F. The interaction of bacteria and metal surfaces. Electrochim. Acta 2007, 52, 7670-7680. [CrossRef]

23. Féron, D.; Dupont, I. Marine Biofilms on Stainless Steels: Effects on the Corrosion Behaviour. In Developments in Marine Corrosion; Woodhead Pub Ltd.: Cambridge, UK, 1998; pp. 89-102.

24. Landolt, D. Corrosion and Surface Chemistry of Metals; Engineering Sciences: Materials; EPFL Press: Lausanne, Switzerland, 2007; Volume 10, ISBN 978-0-8493-8233-8.

25. Videla, H. Biofilms and corrosion interactions on stainless steel in seawater. Int. Biodeterior. Biodegrad. 1994, 34, 245-257. [CrossRef]

26. Stoodley, P.; Sauer, K.; Davies, D.G.; Costerton, J.W. Biofilms as Complex Differentiated Communities. Annu. Rev. Microbiol. 2002, 56, 187-209. [CrossRef]

27. Jia, R.; Unsal, T.; Xu, D.; Lekbach, Y.; Gu, T. Microbiologically influenced corrosion and current mitigation strategies: A state of the art review. Int. Biodeterior. Biodegrad. 2019, 137, 42-58. [CrossRef]

28. Powell, C.; Francis, R. Corrosion Performance of Metals for the Marine Environment: A Basic Guide (EFC 63); CRC Press: Boca Raton, FL, USA, 2012; ISBN 978-1-907975-58-5.

29. Aguirre, J.; Daille, L.; Fischer, D.A.; Galarce, C.; Pizarro, G.; Vargas, I.; Walczak, M.; de la Iglesia, R.; Armijo, F. Study of poly(3,4-ethylendioxythiphene) as a coating for mitigation of biocorrosion of AISI 304 stainless steel in natural seawater. Prog. Org. Coat. 2017, 113, 175-184. [CrossRef]

30. Saha, J. Corrosion of Constructional Steels in Marine and Industrial Environment; Springer: Berlin/Heidelberg, Germany, 2013; ISBN 9783642076442.

31. Kip, N.; van Veen, J.A. The dual role of microbes in corrosion. ISME J. 2015, 9, 542-551. [CrossRef]

32. Videla, H.A. An overview of mechanisms by which sulphate-reducing bacteria influence corrosion of steel in marine environments. Biofouling 2000, 15, 37-47. [CrossRef]

33. Sheng, X.; Ting, Y.-P.; Pehkonen, S.O. The influence of sulphate-reducing bacteria biofilm on the corrosion of stainless steel AISI 316. Corros. Sci. 2007, 49, 2159-2176. [CrossRef]

34. Zhang, P.; Xu, D.; Li, Y.; Yang, K.; Gu, T. Electron mediators accelerate the microbiologically influenced corrosion of 304 stainless steel by the Desulfovibrio vulgaris biofilm. Bioelectrochemistry 2015, 101, 14-21. [CrossRef] 
35. Herrera, L.K.; Videla, H.A. Role of iron-reducing bacteria in corrosion and protection of carbon steel. Int. Biodeterior. Biodegrad. 2009, 63, 891-895. [CrossRef]

36. Marty, F.; Gueuné, H.; Malard, E.; Sánchez-amaya, J.M.; Sjögren, L.; Abbas, B. Identification of key factors in Accelerated Low Water Corrosion through experimental simulation of tidal conditions: Influence of stimulated indigenous microbiota. Biofouling 2014, 30, 281-297. [CrossRef]

37. Zhang, T.; Fang, H.H.P.; Ko, B.C.B. Methanogen population in a marine biofilm corrosive to mild steel. Appl. Microbiol. Biotechnol. 2003, 63, 101-106. [CrossRef]

38. Rajasekar, A.; Anandkumar, B. Characterization of corrosive bacterial consortia isolated from petroleum-product-transporting pipelines. Appl. Microbiol. Biotechnol. 2010, 85, 1175-1188. [CrossRef]

39. Lee, Y.K.; Kwon, K.; Cho, K.H.; Kim, H.W.; Park, J.H.; Lee, H.K. Culture and Identification of Bacteria from Marine Biofilms. J. Microbiol. 2003, 41, 183-188.

40. Celikkol-Aydin, S.; Gaylarde, C.C.; Lee, T.; Melchers, R.E.; Witt, D.L.; Beech, I.B. 16S rRNA gene profiling of planktonic and biofilm microbial populations in the Gulf of Guinea using Illumina NGS. Mar. Environ. Res. 2016, 122, 105-112. [CrossRef] [PubMed]

41. Eashwar, M.; Subramanian, G.; Palanichamy, S.; Rajagopal, G.; Madhu, S.; Kamaraj, P. Cathodic behaviour of stainless steel in coastal Indian seawater: Calcareous deposits overwhelm biofilms. Biofouling 2009, 25, 191-201. [CrossRef] [PubMed]

42. ASTM. ASTM International ASTM G1-03 (Reapproved 2017) Standard Practice for Preparing, Cleaning, and Evaluating Corrosion Test 1-9; ASTM: West Conshohocken, PA, USA, 2017.

43. Fischer, D.A.; Daille, L.; Aguirre, J.; Galarce, C.; Armijo, F. Corrosion of Stainless Steel in Simulated Tide of Fresh Natural Seawater of South East Pacific. Int. J. Electrochem. Sci. 2016, 11, 6873-6885. [CrossRef]

44. Schädler, S.; Burkhardt, C.; Kappler, A. Evaluation of Electron Microscopic Sample Preparation Methods and Imaging Techniques for Characterization of Cell-Mineral Aggregates. Geomicrobiol. J. 2008, 25, 228-239. [CrossRef]

45. Fuhrman, J.A.; Comeau, D.E.; Hagström, A.; Chan, A.M. Extraction from natural planktonic microorganisms of DNA suitable for molecular biological studies. Appl. Environ. Microbiol. 1988, 54, 1426-1429. [CrossRef]

46. Muyzer, G.; de Waal, E.C.; Uitterlinden, A.G. Profiling of complex microbial populations by denaturing gradient gel electrophoresis analysis of polymerase chain reaction-amplified genes coding for 16S rRNA. Appl. Environ. Microbiol. 1993, 59, 695-700. [CrossRef]

47. Tamura, K.; Stecher, G.; Peterson, D.; Filipski, A.; Kumar, S. MEGA6: Molecular evolutionary genetics analysis version 6.0. Mol. Biol. Evol. 2013, 30, 2725-2729. [CrossRef]

48. Huber, T.; Faulkner, G.; Hugenholtz, P. Bellerophon: A program to detect chimeric sequences in multiple sequence alignments. Bioinformatics 2004, 20, 2317-2319. [CrossRef]

49. Altschul, S.F.; Gish, W.; Miller, W.; Myers, E.W.; Lipman, D.J. Basic local alignment search tool. J. Mol. Biol. 1990, 215, 403-410. [CrossRef]

50. Tamura, K.; Nei, M. Estimation of the number of nucleotide substitutions in the control region of mitochondrial DNA in humans and chimpanzees. Mol. Biol. Evol. 1993, 10, 512-526. [PubMed]

51. Li, S.; Li, L.; Qu, Q.; Kang, Y.; Zhu, B.; Yu, D.; Huang, R. Extracellular electron transfer of Bacillus cereus biofilm and its effect on the corrosion behaviour of 316L stainless steel. Colloids Surf. B Biointerfaces 2019, 173, 139-147. [CrossRef] [PubMed]

52. Lee, J.W.; Nam, J.H.; Kim, Y.H.; Lee, K.H.; Lee, D.H. Bacterial communities in the initial stage of marine biofilm formation on artificial surfaces. J. Microbiol. 2008, 46, 174-182. [CrossRef] [PubMed]

53. Rampadarath, S.; Bandhoa, K.; Puchooa, D.; Jeewon, R.; Bal, S. Early bacterial biofilm colonizers in the coastal waters of Mauritius. Electron. J. Biotechnol. 2017, 29, 13-21. [CrossRef]

54. Pollet, T.; Berdjeb, L.; Garnier, C.; Durrieu, G.; Le Poupon, C.; Misson, B.; Briand, J.-F. Prokaryotic community successions and interactions in marine biofilms: The key role of Flavobacteriia. FEMS Microbiol. Ecol. 2018, 94, fiy083. [CrossRef]

55. Phan, H.C.; Wade, S.A.; Blackall, L.L. Is marine sediment the source of microbes associated with accelerated low water corrosion? Appl. Microbiol. Biotechnol. 2019, 103, 449-459. [CrossRef]

56. Makita, H. Iron-oxidizing bacteria in marine environments: Recent progresses and future directions. World J. Microbiol. Biotechnol. 2018, 34,1-13. [CrossRef]

57. McBeth, J.M.; Emerson, D. In Situ Microbial Community Succession on Mild Steel in Estuarine and Marine Environments: Exploring the Role of Iron-Oxidizing Bacteria. Front. Microbiol. 2016, 7, 767. [CrossRef] 
58. McBeth, J.M.; Little, B.J.; Ray, R.I.; Farrar, K.M.; Emerson, D. Neutrophilic iron-oxidizing “Zetaproteobacteria” and mild steel corrosion in nearshore marine environments. Appl. Environ. Microbiol. 2011, 77, 1405-1412. [CrossRef]

59. Dang, H.; Chen, R.; Wang, L.; Shao, S.; Dai, L.; Ye, Y.; Guo, L.; Huang, G.; Klotz, M.G. Molecular characterization of putative biocorroding microbiota with a novel niche detection of Epsilon- and Zetaproteobacteria in Pacific Ocean coastal seawaters. Environ. Microbiol. 2011, 13, 3059-3074. [CrossRef]

60. Rosenberg, E.; DeLong, E.F.; Lory, S.; Stackebrandt, E.; Thompson, F. (Eds.) The Prokaryotes; Springer: Berlin/Heidelberg, Germany, 2014; ISBN 978-3-642-38953-5.

61. Dang, H.; Klotz, M.G.; Lovell, C.R.; Sievert, S.M. Editorial: The Responses of Marine Microorganisms, Communities and Ecofunctions to Environmental Gradients. Front. Microbiol. 2019, 10, 1-5. [CrossRef] [PubMed]

62. Moradi, M.; Song, Z.; Xiao, T. Exopolysaccharide produced by Vibrio neocaledonicus sp. as a green corrosion inhibitor: Production and structural characterization. J. Mater. Sci. Technol. 2018, 34, 2447-2457. [CrossRef]

(C) 2020 by the authors. Licensee MDPI, Basel, Switzerland. This article is an open access article distributed under the terms and conditions of the Creative Commons Attribution (CC BY) license (http://creativecommons.org/licenses/by/4.0/). 